\title{
Effects of High Dose Methotrexate and Delayed Elimination on Myelotoxicity Progression in Children with Acute Lymphoblastic Leukemia
}

\author{
Omar Y. El-Azzazy ${ }^{1}$, Manar M. Fathy ${ }^{2}$, Usama R.El-Safy ${ }^{2}$, \\ Hassan M. El Fayoumi ${ }^{3}$ \\ ${ }^{1}$ Department of Pharmacy Practice, Faculty of Pharmacy, Zagazig University, Egypt. \\ ${ }^{2}$ Pediartic Oncology Unit,Pediatric Department, Faculty of Medicine, Zagazig University, Egypt. \\ ${ }^{3}$ Department of Pharmacology, Faculty of Pharmacy, Zagazig University,Egypt.
}

\section{Corresponding Author \\ Usama R. El-Safy}

\section{E mail:} usamasafy@gmail.com

Key words: HDMTX, ALL, myelosupression, blood count
Background and study aim: Methotrexate (MTX) as an antineoplastic agent inhibits dihydrofolate reductase. The frequency of high dose methotrexate (HDMTX) associated toxicity is variable. In this study we investigate the frequency of myelosuppression following 5 and 9 days of HDMTX infusion and MTX delayed elimination in subsequent MTX cycles in children with Acute lymphoblastic Leukemia (ALL).

Patients and Methods: This study included 28 children diagnosed with ALL during the period between May2014 to April 2016. Complete blood counts were measured before and after 5 and 9 days of HDMTX infusion and MTX levels at $42 \mathrm{~h}$ in 28 children with ALL. The HD-MTX dose is $5 \mathrm{gm} / \mathrm{m} 2$ during 102 infusion of HD MTX at consolidation phase of ALL therapy. The MTX levels at $42 \mathrm{~h}$ in patients with and without toxicity were compared to evaluate the correlation between MTX levels and myelotoxicity.

Results: MTX infusion induced significant reduction in levels of TLC, ANC, RBCs, $\mathrm{Hb}$ and significant elevation of PLT count

\section{INTRODUCTION}

Methotrexate (MTX) is an analogue of aminopetrin and the most widely antifolate used in the treatment of certain neoplastic disease, sever psoriasis and adult rheumatoid arthritis [1]. Methotrexate (MTX) was first applied as a treatment for malignant diseases in oncology in 1948 [2]. It is an important component of the consolidation and maintenance therapy of childhood ALL $[2,3]$. It inhibits dihydrofolate reductase after 5 days of MTX administration. Additionally, after9 days of MTX infusion, there is significant decrease in TLC, ANC, and RBCs levels. However, no significant difference in the PLT count and $\mathrm{Hb}$ level occurred. There is gradual decrease in myelotoxicity after 5 days and increase after 9 days of MTX administration with regard to MTX cycles. There is no statistical difference in MTX level at $42 \mathrm{~h}$ between patients with and without myelotoxicity after 5 and 9 days of MTX infusion. MTX delayed elimination observed in MTX cycles 1, 2, 3 and 4 was $42.8 \% \quad(n=12), \quad 42.8 \% \quad(n=12), \quad 57.1 \%$ $(\mathrm{n}=16)$ and $72 \%(\mathrm{n}=13)$ respectively.

Conclusion: Myelotoxicity was decreased after 5 days of MTX administration and increased after 9 days with regard to MTX cycles. There is no correlation between MTX plasma concentration after $42 \mathrm{~h}$ and hematologic toxicity. Therefore, we cannot depend on MTX levels at $42 \mathrm{~h}$ to anticipate and predict hematologic toxicity.

and was initially developed as an antineoplastic agent [4].

High-dose methotrexate (HDMTX) chemotherapy with leucovorin (LV) rescue is administered to prevent extramedullary infiltration and it is very important ALL therapy [5]. Unfortunately, MTX therapy may lead to myelosuppression, acute liver toxicity, nephrotoxicity, mucositis, and neurotoxicity[4,6-11].MTX-associated toxicity is associated with several factors 
including dose, the duration of administration, patient risk factors, and genetic factors $[\mathbf{1 2 , 1 3}$. There are no sufficient data involving the use of HDMTX pharmacokinetic and toxicity information to anticipate hematologic toxicity in children with ALL.

Delayed MTX elimination was defined by either MTX concentration $>1 \mu \mathrm{mol} / \mathrm{L}$ at $48 \mathrm{~h}$ or $>0.1$ $\mu \mathrm{mol} / \mathrm{L}$ at $72 \mathrm{~h}[\mathbf{1 4 , 1 5}]$. Kidney and/or liver dysfunction, bone marrow suppression, oral mucosal lesions, secondary infection, and delays in the following course of chemotherapy may be a consequence of MTX delayed elimination [6, 16]: Therefore, adjustments of MTX and leucovorin dose, hydration and alkalization were made to minimize the risk of elimination delay/MTX toxicity [16]. Previous reports referred to the effect of some drugs as proton-pump inhibitors, non-steroidal anti-inflammatory drugs, trimethoprim, sulfamethoxazole, penicillins, ciprofloxacin, anticonvulsants such as phenobarbital on delaying MTX elimination [1719].

In this study, we proposed to determine first: the hematologic toxicity and MTX delayed elimination frequency and second: evaluate the relationship between hematologic toxicity and MTX level at 42 hour in children taking $5 \mathrm{gm} / \mathrm{m}^{2}$ MTX infusion during the consolidation phase of ALL therapy.

\section{PATIENTS AND METHODS}

\section{Patient Selection :}

This study was approved by the Committee of Medical Ethics of Zagazig University (IRB number: 2184). ALL subjects include 28 patients, 16 female $(57.1 \%)$ and 12 male $(42.9 \%)$ were recruited from Pediatric Hematology and Oncology Unit Zagazig University during the period between May 2014 and April 2016.

\section{Inclusion criteria :}

a- Both sex included

b- Age 2-18 years

c- ALL patients on high dose methotrexate.

d- In consolidation phase

\section{Exclusion criteria :}

a- Renal failure

b- Liver failure

\section{Protocol of Study :}

According to TOTAL XV protocol, all patients in this study received four HD-MTX doses (5 $\left.\mathrm{g} / \mathrm{m}^{2}\right)$ at 2-week intervals on days $1,15,29$ and 43 of consolidation therapy and 6-mercaptopurine $\left(50 \mathrm{mg} / \mathrm{m}^{2} /\right.$ day) on days 1 to 56 of consolidation therapy. These chemotherapeutics were administered when ANC is $\geq 300 / \mu \mathrm{L}$, and platelet count is $\geq 50 \times 10^{9} / \mathrm{L}$. HDMTX will be held if total bilirubin $2 \mathrm{mg} / \mathrm{dl}$ and direct bilirubin $1.4 \mathrm{mg} / \mathrm{dl}$. However, 6- mercaptopurine may be held in the presence of ANC 300/ $\mu \mathrm{L}$, platelet count 50000/ $\mu \mathrm{L}$ or grade 3 or 4 mucositis. Dosage of 6mercaptopurine subsequent courses may be reduced to $25 \mathrm{mg} / \mathrm{m}^{2} /$ day in patients who have prolonged neutropenia after HDMTX and 6mercaptopurine treatment. At least two hours before HDMTX, prehydration IV fluid $\left(\mathrm{D}_{5} \mathrm{~W}+\right.$ $40 \mathrm{mEq} \mathrm{NaHco}_{3} / \mathrm{L}$ ) will be administered at the rate of $200 \mathrm{ml} / \mathrm{m}^{2} / \mathrm{hr}$ provided that urinary $\mathrm{pH}$ is $\geq 6.5$. Leucovorin $\left[15 \mathrm{mg} / \mathrm{m}^{2}\right.$ IV or PO for standard/high-risk] will be started at $42 \mathrm{hrs}$ after the start of MTX and repeat every $6 \mathrm{hrs}$. The dosage of leucovorin will be increased in patients with high plasma MTX concentrations $(1.0 \mu \mathrm{M}$ at $42 \mathrm{hrs}$ ) and continued until the MTX concentration is less than $0.10 \mu \mathrm{M}$.

\section{Complete Blood Counts and MTX Level Assessments}

In the course of 102 infusions of HD-MTX, the MTX plasma level was measured at $42 \mathrm{~h}$ after HD MTX infusion. Hemoglobin $(\mathrm{Hb})$, absolute neutrophil count (ANC), platelet (PLT) count, red blood count (RBCs) and TLC (total leukocytes count) were determined before MTX administration and on the $5^{\text {th }}$ and $9^{\text {th }}$ day following MTX infusion using Automated Hematology Analyzer. MTX concentration at $42 \mathrm{~h}$ was measured by high performance liquid chromatography (HPLC) assay.

\section{Evaluation of Myelotoxicity}

Hematological toxicity or myelotoxicity signs were determined by absolute neutrophil count and hemoglobin according to Common Terminology Criteria for Adverse Events (CTCAE) [20] (Table 1).

\section{Statistical Analysis :}

Statistical analyses of data were done by Prism 6, Graph pad, CA, USA. Results were expressed as mean \pm standard deviation. Statistical differences were sought using Student's t-test or one way analysis of variance (ANOVA) followed by Fisher's least significant difference (LSD) and or post hoc test (if more than two sets of data were being compared). Differences were considered significant at a $\mathrm{P}<0.05$.

\section{RESULTS}


In this study, there are 102 infusions of HDMTX delivered to twenty eight newly diagnosed acute lymphoblastic leukemia (ALL) patients aged 2-18 years. There is a statistically significant reduction in TLC $(23 \%, \mathrm{P}<0.0001)$, ANC $(22.8 \%$, $\mathrm{P}<0.0001)$, RBCs level $(8.3 \%, \mathrm{P}<0.0001), \mathrm{Hb}$ level $(5.01 \%, \mathrm{P}<0.05)$ and elevation in PLT count $(19.8 \%, \mathrm{P}<0.01)$ after 5 days of MTX infusion compared to before administration data. Additionally, there is a statistically significant reduction in TLC $(18.6 \%, \mathrm{P}<0.0001)$, ANC $(20.3 \%, \mathrm{P}<0.0001)$, RBCs level $(5.5 \%, \mathrm{P}<0.05)$ after 9 days of MTX infusion. Whereas, there is no statistically significant difference in the PLT count and $\mathrm{Hb}$ level after 9 days of MTX infusion (Table 2).

Gradual decrease in myelotoxicity after 5 days of MTX administration was shown. However, there is gradual increase in myelotoxicity after 9 days of MTX administration with regard to MTX cycles (Tables 3-4, Figure 1).

In addition, Table $(5,6)$ show that there is no statistical difference in MTX level at $42 \mathrm{~h}$ between patients with or without myelotoxicity after 5 and/or 9 days of MTX infusion. Figure (2) also illustrates that there is a gradual increase in\% MTX delayed elimination with regard to MTX cycles.

Table (1): Toxicity criteria according to the Common Terminology Criteria for Adverse Events 2010 guideline

\begin{tabular}{|l|c|c|c|c|}
\hline & Grade 1 & Grade 2 & Grade 3 & Grade 4 \\
\hline Hb $(\mathbf{g} / \mathbf{L})$ & LLN-10 & $8-10$ & $<8$ & Life threatening anemia \\
\hline ANC $(\mathbf{x 1 0} / / \mathbf{L})$ & LLN-1.5 & $1.5-1$ & $1-0.5$ & $<0.5$ \\
\hline
\end{tabular}

Table (2): TLC, ANC, RBCs, Hb, and Platelets concentrations before and following 5 and 9 days of administration of MTX in ALL patients. All results were expressed as mean \pm SD

\begin{tabular}{|l|c|c|c|}
\hline & Before MTX Infusion & 5 days & 9 days \\
\hline $\mathrm{TLCx} 10^{3} / \mu \mathrm{L}$ & $3.6 \pm 1.07$ & $2.76 \pm 1.03^{*}$ & $2.93 \pm 1.13^{*}$ \\
\hline $\mathrm{ANC} / \mu \mathrm{L}$ & $1835 \pm 709.9$ & $1416 \pm 538.9^{*}$ & $1462 \pm 578^{*}$ \\
\hline $\mathrm{RBCs} \times 10^{6} / \mu \mathrm{L}$ & $3.6 \pm 0.5$ & $3.3 \pm 0.46^{*}$ & $3.4 \pm 0.53 \mathrm{a}$ \\
\hline $\mathrm{Hb}(\mathrm{g} / \mathrm{dL})$ & $10.56 \pm 1.36$ & $10.03 \pm 1.422 \mathrm{a}$ & $10.37 \pm 1.28$ \\
\hline $\mathrm{PLT} \times 10^{3} / \mu \mathrm{L}$ & $291 \pm 111.9$ & $348.7 \pm 138.2 \mathrm{~b}$ & $303.5 \pm 120.5$ \\
\hline
\end{tabular}

Significantly different from before MTX administration at $* \mathrm{p}<0.0001,{ }^{\mathrm{a}} \mathrm{p}<0.05$ and ${ }^{\mathrm{b}} \mathrm{p}<0.01$

Table (3): Toxicity frequencies after 5 days of MTX administration with regard to MTX cycles in ALL patients

\begin{tabular}{|l|c|c|c|c|}
\hline & $\begin{array}{c}\mathbf{1}^{\text {st }} \text { MTX } \\
(\mathbf{n = 2 8})\end{array}$ & $\begin{array}{c}\mathbf{2}^{\text {nd }} \text { MTX } \\
(\mathbf{n}=\mathbf{2 8})\end{array}$ & $\begin{array}{c}3^{\text {rd }} \text { MTX } \\
(\mathbf{n = 2 8})\end{array}$ & $\begin{array}{c}4^{\text {th }} \text { MTX } \\
(\mathbf{n = 1 8})\end{array}$ \\
\hline $\mathrm{ANC}<1 \times 10^{9} / \mathrm{L}$ & $2(7.1 \%)$ & $4(14.3 \%)$ & $2(7.1 \%)$ & $1(5.5 \%)$ \\
\hline $\mathrm{Hb}<10 \mathrm{~g} / \mathrm{L} \& \mathrm{ANC}<1 \times 10^{9} / \mathrm{L}$ & $9(32.1 \%)$ & $7(25 \%)$ & $3(10.7 \%)$ & $2(11.1 \%)$ \\
\hline Myelotoxicity\% & $39.2 \%$ & $39.3 \%$ & $17.8 \%$ & $16.6 \%$ \\
\hline
\end{tabular}

Table (4): Toxicity frequencies after 9 days of MTX administration with regard to MTX cycles in ALL patients

\begin{tabular}{|l|c|c|c|c|}
\hline & $\begin{array}{c}\mathbf{1}^{\text {st }} \text { MTX } \\
(\mathbf{n = 2 8})\end{array}$ & $\begin{array}{c}\mathbf{2}^{\text {nd }} \text { MTX } \\
(\mathbf{n = 2 8})\end{array}$ & $\begin{array}{c}3^{\text {rd }} \text { MTX } \\
(\mathbf{n = 2 8})\end{array}$ & $\begin{array}{c}\mathbf{4}^{\text {th }} \text { MTX } \\
(\mathbf{n = 1 8})\end{array}$ \\
\hline $\mathrm{ANC}<1 \times 10^{9} / \mathrm{L}$ & $1(3.6 \%)$ & $4(14.3 \%)$ & $7(25 \%)$ & $3(16.7 \%)$ \\
\hline $\mathrm{Hb}<10 \mathrm{~g} / \mathrm{L} \& \mathrm{ANC}<1 \times 10^{9} / \mathrm{L}$ & $7(25 \%)$ & $7(25 \%)$ & $3(10.7 \%)$ & $3(16.7 \%)$ \\
\hline Myelotoxicity \% & $28.6 \%$ & $39.3 \%$ & $35.7 \%$ & $33.4 \%$ \\
\hline
\end{tabular}


Table (5): Correlation of MTX levels at 42 hour in patients with and without hematologic toxicity after 5 days of MTX infusion and distribution with reference to the cycles. All values were expressed as mean $\pm \mathrm{SD}$

\begin{tabular}{|l|c|c|c|}
\hline & Patient with Myelotoxicity & Patient without Myelotoxicity & P value \\
\hline Cycle 1 $(\mathrm{n}=28)$ & $1.01 \pm 0.37(\mathbf{n}=\mathbf{1 1})$ & $0.96 \pm 0.37(\mathbf{n}=\mathbf{1 7})$ & $>0.05$ \\
\hline Cycle 2(n=28) & $0.99 \pm 0.35(\mathbf{n}=\mathbf{1 1})$ & $0.82 \pm 0.32(\mathbf{n}=\mathbf{1 7})$ & $>0.05$ \\
\hline Cycle 3(n=28) & $0.88 \pm 0.27(\mathbf{n}=\mathbf{5})$ & $0.93 \pm 0.34(\mathbf{n}=\mathbf{2 3})$ & $>0.05$ \\
\hline Cycle 4(n=18) & $0.96 \pm 0.33(\mathbf{n}=\mathbf{3})$ & $1.04 \pm 0.29(\mathbf{n}=\mathbf{1 5})$ & $>0.05$ \\
\hline
\end{tabular}

Table (6): Correlation of MTX levels at 42 hour in patients with and without hematologic toxicity after 9 days of MTX infusion and distribution with reference to the cycles. All values were expressed as mean \pm SD

\begin{tabular}{|l|c|c|c|}
\hline & Patient with Myelotoxicity & Patient without Myelotoxicity & P value \\
\hline Cycle 1 $(n=28)$ & $0.94 \pm 0.40(\mathbf{n}=\mathbf{8})$ & $0.96 \pm 0.38(\mathbf{n = 1 8})$ & $>0.05$ \\
\hline Cycle $2(\mathrm{n}=28)$ & $1.05 \pm 0.36(\mathbf{n}=\mathbf{1 1})$ & $0.79 \pm 0.29(\mathbf{n}=\mathbf{1 7})$ & $>0.05$ \\
\hline Cycle $3(\mathrm{n}=28)$ & $1.00 \pm 0.32(\mathbf{n}=\mathbf{1 0})$ & $0.88 \pm 0.33(\mathbf{n}=\mathbf{1 8})$ & $>0.05$ \\
\hline Cycle $4(\mathrm{n}=18)$ & $0.85 \pm 0.28(\mathbf{n}=\mathbf{6})$ & $1.11 \pm 0.25(\mathbf{n}=\mathbf{1 2})$ & $>0.05$ \\
\hline
\end{tabular}

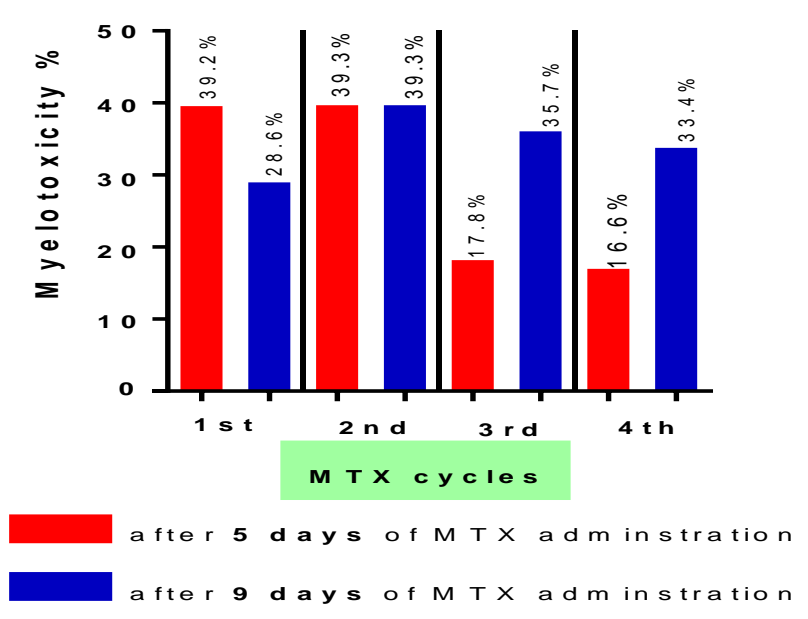

Figure (1): Myelotoxicity percent in different high dose MTX cycles after 5 and 9days of MTX administration in ALL patients

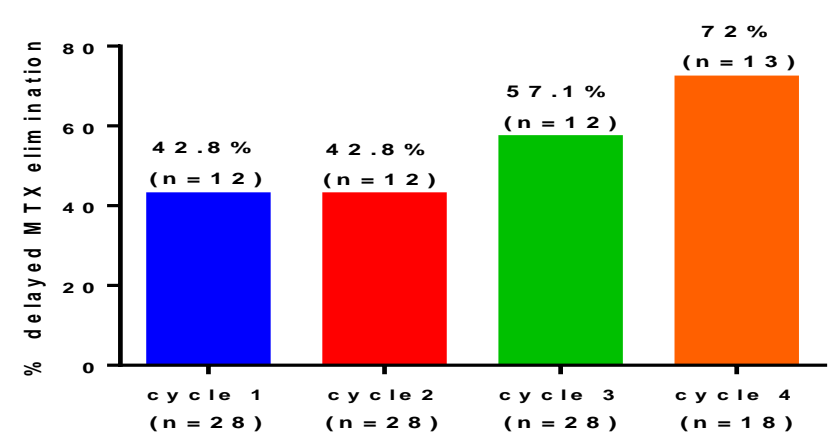

Figure (2): Percentage of delayed MTX elimination with regard to MTX cycles in ALL patients 


\section{DISCUSSION}

Consolidation phase is considered avaluable and important step in the treatment of children with ALL. The use of high dose methotrexate, sometimes in combination with 6-mercaptopurine (6-MP) has significantly contributed to cure children (70$80 \%$ ). In this study administration of MTX infusion for 5 days induced significant reduction in TLC, ANC, RBCs, Hb levels and PLT count after 5 days of MTX infusion. Similar data was observed during 9 days administration except the effect on PLT count and $\mathrm{Hb}$ level. These results are in agreement with previous studies [21]. This effect on blood counts especially RBCs and TLC is attributed to higher concentration of MTXPG in patients whose blast count decreased within 24 $\mathrm{h}$. Blast cells are the origin of platelets, red blood cells, neutrophils and other types of white blood cells in the myeloid cell line [22]. Therefore, decrease in blast concentration of MTXPGLC (MTX polyglutamate long chain) may be strongly related to the rate of inhibition of de novo purine synthesis in ALL blasts [23].

The significant reduction of $\mathrm{Hb}$ after 5 days and the non statistical significant difference of $\mathrm{Hb}$ after 9 days may be justified by the results of de Rotte et al. [24]. Methotrexate can affect HbA1c where, methotrexate use and higher concentrations of erythrocyte MTX Glu (erythrocyte methotrexate polyglutamate) are associated with decreased levels of HbA1c. Therefore, concentrations of erythrocyte MTX Glu may be still high after 5 days of MTX infusion. However, after 9 days, concentrations of erythrocyte MTX Glu may be decreased.

Lexicomp [25] has been reported that not all patients should suffer low blood counts in RBCs, WBCs and platelets but this low blood counts is only common in more than $30 \%$ of patients supporting the present finding where there is no statistically significant difference in the PLT count and $\mathrm{Hb}$ level after 9 days of MTX infusion.

The current study illustrated gradual decrease in hematologic toxicity and myelotoxicity after 5 days of MTX infusion with repeated MTX administrations. These results are consistent with others [26]. Attenuation of hematologic toxicity and myelotoxicity with repeated MTX administrations may be related to HDMTX may be held if total bilirubin $2 \mathrm{mg} / \mathrm{dl}$ and direct bilirubin $1.4 \mathrm{mg} / \mathrm{dl}$ [27]. So the myelotoxicity will be decreased. Additionally, dosage of 6- mercaptopurine may be reduced to $25 \mathrm{mg} / \mathrm{m}^{2} /$ day in patients who have prolonged neutropenia after HDMTX and 6mercaptopurine treatment ${ }^{[27]}$ and this may be a good reason for the gradual decrease of myelotoxicity [21], especially while the degree of myelosuppression and duration of treatment interruptions following HD-MTX is related to the dose of concurrently administered oral 6MP [21,28-30] and can be avoided by reductions of the dose of 6MP in the weeks before and after HD-MTX [31].

On the other hand, there is gradual increase in hematologic toxicity and myelotoxicity after 9 days of MTX infusion with repeated MTX administrations. These results were compatible with other previous reports $[\mathbf{6 , 3 2}]$. Rask et al[6]have been demonstrated that increase in myelosuppression in subsequent cycles of MTX may be related to the accumulation of cytotoxic metabolites of MTX and 6MP. In addition, other studies $[21,29]$ referred to using high dose MTX with increased doses of 6MP may also increase hematologic toxicity.

Interestingly, this study revealed that there is no correlation between MTX plasma concentration after 42 hour and hematologic toxicity. These results were supported by Özdemir et al. [32]. They documented that the MTX levels at $42 \mathrm{~h}$ in patients with myelotoxicity were not different from patients without toxicity. Additionally, Csordas et al. [33] did not find any correlation between myelotoxicity and the levels of serum MTX. However, other studies reported that there is a relationship between elevated serum MTX levels and hematologic toxicity [6].

This study explore that there is a gradual increase in MTX delayed elimination with regard to MTX cycles. This may be consistent with the results of Bauters et al. [34]. They reported that high MTX levels $(72 \mathrm{~h})$ were frequently observed upon intake of cola beverages. Higher MTX levels were more common after intake of cola during the first and/or second day after the start of HDMTX infusion. Santucci et al. [35] explained that Cola beverages have a low $\mathrm{pH}$ due to their phosphoric acid content and that may explain its effect on MTX elimination.

\section{CONCLUSION}

There is gradual decrease in myelotoxicity after 5 days of MTX administration with regard to MTX cycles. However, there is gradual increase in myelotoxicity after 9 days of MTX administration with regard to MTX cycles. There 
is no correlation between MTX plasma concentration after $42 \mathrm{~h}$ and hematologic toxicity. Therefore, we cannot depend on MTX levels at $42 \mathrm{~h}$ to anticipate and predict hematologic toxicity. Moreover, there is a gradual increase in MTX delayed elimination with regard to MTX cycles.

Funding: None.

Conflicts of interest: None.

Ethical Approval: The study was approved by the Committee of Medical Ethics of Zagazig University (IRB number: 2184) and a written informed consent was taken from each participant that follows the principals in the declaration of Helsinki.

\section{REFERENCES}

1. Chu E, Takechi T, Jones K, Voeller D, Copur S, Maley $\mathrm{G}$ et al. Thymidylate synthase binds to cmyc RNA in human colon cancer cells and in vitro. Mol Cell Biol, 1995; 15(1): 179-85.

2. Miller D. A tribute to Sidney Farber-the father of modern chemotherapy. British Journal of Haematology 2006; 134(1): 20-26.

3. Pui C, Robison L, and Look T. Acute lymphoblastic leukaemia. The Lancet 2008; 371(9617): 10301043.

4. Khan Z,Tripathi R, Mishra B. Methotrexate: a detailed review on drug delivery and clinical aspects. Expert Opinion on Drug Delivery; 2012; 9(2): 151-169.

5. Pui C. Recent research advances in childhood acute lymphoblastic leukemia. Journal of the Formosan Medical Association 2010; 109(11): 777-787.

6. Rask C, Albertioni F, Bentzen S, Schroeder H, Peterson $\mathrm{C}$. Clinical and pharmacokinetic risk factors for high-dose methotrexate-induced toxicity in children with acute lymphoblastic leukemia: a logistic regression analysis. Acta Oncologica 1998; 37(3): 277-284.

7. Fisgin T, Yarali N, Kara A, Bozkurt C, Birgen D, Erten $U$ et al. Hemostatic side effects of highdose methotrexate in childhood acute lymphoblastic leukemia. Pediatric Hematology and Oncology; 2004; 21(1): 77-83.

8. Van Outryve S, Schrijvers D, Van Den B, Wilmes P, Bogers J, Van M et al. Methotrexateassociated liver toxicity in a patient with breast cancer: case report and literature review. Neth $J$ Med; 2002; 60(5): 216-222.

9. Inaba H, Khan R, Laningham F, Crews K, Pui C, Daw N. Clinical and radiological characteristics of methotrexate-induced acute encephalopathy in pediatric patients with cancer. Annals of Oncology; 2007; 466.

10. Kaur I, Dogra S, De D, Kanwar A. Systemic methotrexate treatment in childhood psoriasis: further experience in 24 children from India. Pediatric Dermatology; 2008; 25(2): 184-188.

11. Widemann B and Adamson P. Understanding and managing methotrexate nephrotoxicity. The Oncologist; 2006; 11(6): 694-703.

12. Neuman M, Cameron R, Haber J, Katz G, Malkiewicz L, Shear N et al. Inducers of cytochrome P450 2E1 enhance methotrexate-induced hepatocytotoxicity. Clinical Biochemistry; 1999; 32(7): 519-536.

13. Shimasaki N, Mori T, Samejima H, Sato R, Shimada H, Yahagi N et al. Effects of methylene tetrahydrofolatere ductase and reduced folate carrier 1 polymorphisms on high-dose methotrexate-induced toxicities in children with acute lymphoblastic leukemia or lymphoma. Journal of Pediatric Hematology/Oncology 2006; 28(2): 64-68.

14. Stoller R, Hande K, Jacobs S, Rosenberg S, Chabner B. Use of plasma pharmacokinetics to predict and prevent methotrexate toxicity. New England Journal of Medicine, 1977; 297(12): 630-634.

15. Evans W, Schentag J, Jusko W. Applied pharmacokinetics: principles of therapeutic drug monitoring 1992: Applied Therapeutics, Incorporated.

16. Xu W, Tang $\mathrm{Y}$, Song $\mathrm{H}$, Shi S, Yang S. Retrospective study on elimination delay of methotrexate in high-dose therapy of childhood acute lymphoblastic leukemia in China. Journal of Pediatric Hematology/Oncology; 2007; 29(10): 688-693.

17. Levêque D, Santucci, R, Gourieux, B, Herbrecht, R. Pharmacokinetic drug-drug interactions with methotrexate in oncology. Expert Review of Clinical Pharmacology; 2011; 4(6): 743-750.

18. Bezabeh S, Mackey A, Kluetz P, Jappar D, Korvick J. Accumulating evidence for a drugdrug interaction between methotrexate and proton pump inhibitors. The Oncologist; 2012; 17(4): 550-554.

19. Bauters T, Lammens T, Belin P, Benoit $\mathrm{Y}$, Robays H, De Moerloose B. Interaction between methotrexate and omeprazole in an adolescent with leukemia: a case report. Pharmacy World \& Science; 2008; 30(4): 316-318.

20. Health US Department, Human Services. Common Terminology Criteria for Adverse Events (CTCAE) 2016; Version 4.0. 
21. Levinsen, M., et al. Myelotoxicity after high-dose methotrexate in childhood acute leukemia is influenced by 6-mercaptopurine dosing but not by intermediate thiopurinemethyltransferase activity. Cancer Chemotherapy and Pharmacology; 2015; 75(1): 59-66.

22. Ezzone S. Hematopoietic stem cell transplantation: A Manual for Nursing Practice 2004; p. 1 online resource (344 pages).

23. Masson E, Relling M, Synold T, Liu Q, Schuetz $\mathrm{J}$, Sandlund J et al. Accumulation of methotrexate polyglutamates in lymphoblasts is a determinant of antileukemic effects in vivo. A rationale for high-dose methotrexate. J Clin Invest; 1996; 97(1): 73-80.

24. de Rotte M, de Jong P, den Boer E, Pluijm S, Özcan B, WeelA et al. Effect of Methotrexate Use and Erythrocyte Methotrexate Polyglutamate on Glycosylated Hemoglobin in Rheumatoid Arthritis. Arthritis \& Rheumatology; 2014; 66(8): 2026-2036.

25. Lexicomp Online ${ }^{\circledR}$ Methotrexate. Lexi-Drugs ${ }^{\circledR}$ 2015.

26. Ridolfi L, Barisone E, Vivalda M, Vivenza C, Brach D, Leone L et al. Toxicity of high dose methotrexate repeated infusions in children treated for acute lymphoblastic leukemia and osteosarcoma. Minerva Pediatrica; 1996; 48(5): 193-200.

27. Pui C, Relling M, Sandlund J, Downing J, Campana D, Evans W et al. Rationale and design of Total Therapy Study XV for newly diagnosed childhood acute lymphoblastic leukemia. Ann Hematol; 2004; 83 (Suppl 1): S124-126.

28. Schmiegelow K, Bretton-Meyer U. 6mercaptopurine dosage and pharmacokinetics influence the degree of bone marrow toxicity following high-dose methotrexate in children with acute lymphoblastic leukemia. Leukemia; $2001 ; 15(1)$.

29. van KootenNiekerk P, Schmiegelow K, Schroeder H. Influence of methylene tetrahydrofolatere ductase polymorphisms and coadministration of antimetabolites on toxicity after high dose methotrexate. European Journal of Haematology; 2008; 81(5): 391-398.

30. Baxmann A, Ahmed M, Marques N, Menon V, Pereira A, Kirsztajn G et al. Influence of muscle mass and physical activity on serum and urinary creatinine and serum cystatin C. Clin J Am Soc Nephrol; 2008; 3(2): 348-354.

31. Nygaard U, Schmiegelow K. Dose reduction of coadministered 6-mercaptopurine decreases myelotoxicity following high-dose methotrexate in childhood leukemia. Leukemia; 2003; 17(7): 1344-1348.

32. Özdemir Z, Turhan A, Kar Y, Bör Ö. The frequency of hepatotoxicity and myelotoxicity in leukemic children with different high doses of methotrexate. International Journal of Pediatrics and Adolescent Medicine; 2016.

33. Csordas K, Hegyi M, Eipel O, Muller J, Erdelyi D, Kovacs G. Comparison of pharmacokinetics and toxicity after high-dose methotrexate treatments in children with acute lymphoblastic leukemia. Anti-Cancer Drugs; 2013; 24(2): 189 197.

34. Bauters $\mathrm{T}$, Lammens $\mathrm{T}$, Belin $\mathrm{P}$, Benoit $\mathrm{Y}$, Robays H, De Moerloose B. Delayed elimination of methotrexate by cola beverages in a pediatric acute lymphoblastic leukemia population. Leukemia \& Lymphoma; 2013; 54(5): 1094-1096.

35. SantucciR, Levêque D, Herbrecht R. Cola beverage and delayed elimination of methotrexate. British Journal of Clinical Pharmacology; 2010; 70(5): 762-764. 